\title{
Knowledge, Acceptability, Perception and Stigmas on Safe Abortion among the women of reproductive age group (15-49 years) in Bhaktapur District
}

\author{
Ankisha Shrestha ${ }^{1}$, Ram Chandra Sinha ${ }^{2}$ and Aalia Ahmad ${ }^{2}$
}

${ }^{1}$ Department of Public Health, Nobel College, Nepal Health Professional Council, Kathmandu, Nepal ${ }^{2}$ Department of Public Health, Nobel College, Kathmandu, Nepal

\begin{abstract}
Introduction: The termination of pregnancy by the removal of a foetus or an embryo before surviving outside the uterus or before attaining its viability is called abortion. This study was conducted to study the knowledge, acceptability, perception and stigma of safe abortion among women of reproductive age group.

Methods: A cross-sectional analytical study was carried out in Bhaktapur District, Nepal from July 2019 to December 2019. Women of reproductive age group were included in the study. The semi-structured questionnaires were used as a data collection tool and Likert scales were used for perception and stigma which were self-designed. For Likert scale on perception and stigma, Cronbach's $\alpha$ was calculated from the pre-tested samples which was found to be acceptable i.e., 0.649 and 0.856 . Interview was taken as data collection technique. Data-entry was done in Epi-Data and analysed through SPSS 16.0. Chi square test was used to measure the association between dependent and independent variables.

Result: The association between "Knowledge and Perception" was found to be significant with p-value of 0.04 , the association between "Knowledge and Stigma" was also noted to be significant with p-value of 0.00 and "Knowledge and Acceptability" was also found to be significant with p-value of 0.00 through the assessment of knowledge, acceptability, perception and stigma.
\end{abstract}

Conclusions: The study emphasises on educating and making aware every woman on safe abortion, its legalisation and its amended law to avoid the stigma and unsafe abortion practices.

Key words: embryo; foetus; pregnancy; termination; viability

Correspondence: Ankisha Shrestha, Department of Public Health, Nobel College, Nepal Health Professional Council, Kathmandu Nepal, Email: ankeeca@gmail.com

DOI: $10.3126 /$ mjsbh.v20i2.37426

Submitted on: 2021-06-02

Accepted on: 2021-06-21 


\section{INTRODUCTION}

The termination of pregnancy by the removal of a foetus or an embryo before surviving outside the uterus or before acquiring its viability is called abortion. ${ }^{1}$ There are two types of abortion; induced abortion and spontaneous abortion. The illegal, intentional termination of a pregnancy done without the supervision or guidance of the professionally trained health care providers which can threaten life is called unsafe abortion. ${ }^{2}$

Despite being legalised and accepted by the Government in $2002 \mathrm{AD}$, the misconception, and the stigma still exist in the society today. ${ }^{3}$ Those women who undergo through the abortion services are still abandoned. Most women and people are still unaware of the legalisation of safe abortion services which lead to unsafe abortion practices. The unsafe abortion practices due to the optimistic perception of society towards abortion has contributed much to maternal mortality and morbidity in Nepal and worldwide. ${ }^{2}$

The aim of this research is also to make women aware about the legalisation of abortion, safe abortion practices and services. We intended to study the association between 'knowledge and perception', 'knowledge and stigma' and 'knowledge and acceptability' on abortion through assessing the knowledge, acceptability, perception and stigma on safe abortion among the women of reproductive age group in Bhaktapur District, Nepal. Our study is expected to help to explore the knowledge regarding the abortion and help them aware about the safe abortion services available. It can also guide women about the safe abortion and aware them about the consequences and complications of unsafe abortion. Moreover, this research can also help to change the perception and exploit the stigmas related abortion to some extent.

\section{METHODS}

A cross-sectional analytical study was carried out for 6 months from July 2019 till December 2019 .

Table 1. Knowledge on abortion

\begin{tabular}{|l|r|c|}
\hline Knowledge on abortion & $\mathrm{n}$ & $\%$ \\
\hline Low & 156 & $55.31 \%$ \\
\hline High & 126 & $44.68 \%$ \\
\hline
\end{tabular}

Research approval was taken from Institutional Review Committee of Nobel College and formal permission was taken from the municipalities and the ward offices and the verbal consent was taken from the respondents as ethical consideration. Parental consent was also taken for the respondents below 18 years of age group. Confidentiality and dignity were also maintained and the obtained responses and information were used only for the purpose of the study. Three wards from each four municipalities of Bhaktapur District, Nepal were selected through simple random sampling technique. A total of 282 respondents were selected from clustered sampling technique using prevalence rate of safe abortion in Nepal during 2019 i.e., $21.1 \%$ with formula $n=z^{2} p q / d^{2}$. Only women of reproductive age group (15 to 49 years) were included in the study. The semi-structured questionnaires were used as a data collection tool and Likert scales were used for perception and stigma which were self-designed. Validity and reliability were established by calculating Cronbach's $\alpha$ for the Likert scale from the pretested samples which was found to be acceptable i.e. 0.649 for perception and 0.856 for stigma. Pretesting was done among $10 \%$ of the total estimated sample i.e., 28 women in Kathmandu valley. Interview was taken as data collection technique. Data-entry was done in Epi-Data and analysed through SPSS. Chi square test was used to measure the association between dependent (knowledge) and independent (acceptability, perception and stigma) variables.

\section{RESULT}

Total 282 women participated in the survey. All the participants completed the questionnaire. According to their socio-demographic characteristics, $6.03 \%$ of the respondents were of age group (15 - 19 years), $31.56 \%$ were of age group ( $20-29$ years), $30.50 \%$ were of age group (30 - 39 years) and the remaining $31.91 \%$ were of age group (40 - 49 years). From ethnicity, majority

Table 2. Perception on abortion

\begin{tabular}{|l|r|l|}
\hline Perception on abortion & \multicolumn{1}{|c|}{$\mathrm{n}$} & \multicolumn{1}{l}{$\%$} \\
\hline Negative & 187 & $66.31 \%$ \\
\hline Positive & 95 & $33.68 \%$ \\
\hline
\end{tabular}


Table 3. Acceptability on abortion

\begin{tabular}{|l|r|c|}
\hline Acceptability on abortion & \multicolumn{1}{l|}{ n } & $\%$ \\
\hline Yes & 164 & $58.15 \%$ \\
\hline No & 118 & $41.84 \%$ \\
\hline
\end{tabular}

of them were janajati rather than other ethnicities. $31.56 \%$ of the respondents were homemakers, $8.51 \%$ of the respondents were engaged in agriculture, $18.79 \%$ were engaged in business, $26.95 \%$ were involved in service whereas $14.18 \%$ were students and engaged in other occupations. $23.40 \%$ of the respondents were unmarried and $76.60 \%$ married. For Likert scale on perception and stigma Scale, Cronbach's $\alpha$ was calculated from the pre-tested samples which was found to be acceptable i.e., 0.649 and 0.856 respectively.

Table 5 shows the cross tabulation between knowledge and perception on abortion among the respondents. It was found that $58.97 \%$ had low knowledge and negative perception on abortion whereas, $41.02 \%$ had low knowledge yet positive perception on abortion. Similarly, $75.39 \%$ had high knowledge yet negative perception on abortion and $24.60 \%$ had high knowledge and positive perception on abortion. Therefore, majority of the women i.e., $66.31 \%$ had negative perception on abortion and only $33.68 \%$ had positive perception on abortion. Since the p-value was 0.04 i.e. (< 0.465 ), association between knowledge and perception on safe abortion was found to be statically significant.

Table 6 shows the cross tabulation between knowledge and stigma on abortion among the respondents. It was found that $42.94 \%$ had low knowledge and negative response towards abortion i.e., they followed stigma whereas, $57.05 \%$ had low knowledge yet positive response towards abortion

Table 5. Cross-tabulation showing p-value of Chisquare test between respondent's Knowledge and Perception on safe abortion

\begin{tabular}{|l|r|r|r|r|r|r|}
\hline Knowledge & \multicolumn{4}{|c|}{ Perception } & Total & p- \\
& \multicolumn{1}{|c|}{ Negative } & \multicolumn{2}{c|}{ Positive } & & value \\
& N & $\%$ & N & $\%$ & & \\
\hline Low & 92 & 58.97 & 64 & 41.02 & 156 & 0.04 \\
High & 95 & 75.39 & 31 & 24.60 & 126 & \\
Total & 187 & 66.31 & 95 & 33.68 & 282 & \\
\hline
\end{tabular}

Table 4. Stigmas on abortion

\begin{tabular}{|l|l|l|}
\hline Stigmas on abortion & \multicolumn{1}{l}{$\mathrm{n}$} & $\%$ \\
\hline Negative & 153 & $54.25 \%$ \\
\hline Positive & 129 & $45.74 \%$ \\
\hline
\end{tabular}

i.e., they do not follow stigma. Similarly, $68.25 \%$ had good knowledge yet negative response towards abortion i.e., despite of having adequate knowledge, they follow stigma and $31.74 \%$ had adequate knowledge and positive response towards abortion. Therefore, majority of the women $54.25 \%$ were stigmatised on abortion and remaining $45.74 \%$ had positive response towards abortion. Since the p-value was 0.00 i.e. $(<0.465)$, association between knowledge and stigma on safe abortion was found to be statically significant.

Table 7 shows the cross tabulation between knowledge and acceptability on abortion among the respondents. It was found that $39.10 \%$ of the respondents had low knowledge on abortion yet accepted it and $69.10 \%$ had low knowledge and did not accept abortion. Similarly, $81.70 \%$ of the respondents had high knowledge on abortion and accepted abortion whereas, $18.30 \%$ respondents despite having high knowledge on abortion did not accept it. Therefore, majority of women i.e., $51.20 \%$ accepted the abortion and remaining $41.80 \%$ did not. Since the p-value was 0.00 i.e. (< $0.465)$, association between knowledge and acceptability on safe abortion was found to be statically significant.

\section{DISCUSSION}

Abortion is the termination of pregnancy by the removal of a foetus or an embryo before surviving outside the uterus or before acquiring its viability. ${ }^{1}$ The study has assessed the knowledge,

Table 6. Cross-tabulation showing p-value of Chisquare test between respondent's Knowledge and Stigma on safe abortion

\begin{tabular}{|c|c|c|c|c|c|c|}
\hline \multirow[t]{3}{*}{ Knowledge } & \multicolumn{4}{|c|}{ Stigma } & \multirow{3}{*}{$\begin{array}{c}\text { Tota } \\
\text { l }\end{array}$} & \multirow{3}{*}{$\begin{array}{c}\text { p- } \\
\text { valu } \\
\text { e }\end{array}$} \\
\hline & \multicolumn{2}{|c|}{ Negative } & \multicolumn{2}{|c|}{ Positive } & & \\
\hline & n & $\%$ & n & $\%$ & & \\
\hline Low & 67 & $42.94 \%$ & 89 & $57.05 \%$ & 156 & 0.00 \\
\hline High & 86 & $68.25 \%$ & 40 & $31.74 \%$ & 126 & \\
\hline Total & 153 & $54.25 \%$ & 129 & $45.74 \%$ & 282 & \\
\hline
\end{tabular}


Table 7. Cross-tabulation showing p-value of Chisquare test between respondent's Knowledge and Acceptability on safe abortion

\begin{tabular}{|l|r|r|r|r|r|r|}
\hline \multirow{2}{*}{ Knowledge } & \multicolumn{4}{|c|}{ Acceptability } & Total & $\begin{array}{c}\text { p- } \\
\text { value }\end{array}$ \\
\cline { 1 - 6 } & \multicolumn{2}{|c}{ Yes } & \multicolumn{1}{c}{ No } & & \\
\hline Low & 91 & 39.1 & 65 & 69.1 & 156 & 0.00 \\
High & 73 & 81.7 & 53 & 18.3 & 126 & \\
Total & 164 & 51.2 & 118 & 41.8 & 282 & \\
\hline
\end{tabular}

*0 cells (.0\%) have expected count less than 5. The minimum expected count is 52.72

acceptability, perception and stigma on safe abortion among the women of reproductive age group (15 - 49 years) in Bhaktapur District, Nepal. The associations between "Knowledge and Perception", "Knowledge and Stigma" and "Knowledge and Acceptability" were also identified.

In a cross-sectional study among 405 mid-level providers (MLPs), $71.9 \%$ knew the meaning of abortion, $81.5 \%$ of them were updated about the abortion law. $53.1 \%$ of respondents had sufficient information on safe foetus removal care. Only $20.5 \%$ of MLPs were prepared on safe foetus removal and among them $81.9 \%$ were used to practice safe abortion administrations. $54.1 \%$ respondents had positive attitude towards abortion. ${ }^{4}$ A similar cross-sectional study was done where $80.6 \%$ of the total participants rejected abortion among which $57.7 \%$ of the respondents rejected despite the recommendation from medical personnel and $35.4 \%$ supported only for the safety of mother's health and life. $68.6 \%$ and $73.1 \%$ of the respondents did not support the spouse and parental consent respectively and $70.3 \%$ of the participants rejected the consent. $69.7 \%$ of the participants were aware about the complications of elective abortions. ${ }^{5}$ Similarly in a cross-sectional study carried out among 422 individuals, $56.4 \%$ of the participants were in favour of legalisation of induced abortion. However, only $5.7 \%$ of the respondents had knowledge on current legal status of abortion. Association between 'Knowledge abortion complication and preference to terminate unwanted pregnancy and attitude towards legalisation of abortion' was found statistically significant i.e. $\mathrm{p}$ - value $<0.005){ }^{6}$
Compared to the above studies, we could find that only $44.68 \%$ of women had proper knowledge on abortion and its legalisation and very less participants i.e., $33.70 \%$ perceived the safe abortion practice positively. Association between "Knowledge and Perception", "Knowledge and Stigma" and "Knowledge and Acceptability" were found to be $0.04,0.00$ and 0.00 respectively, i.e., statistically significant. We could see that the knowledge of the respondents on abortion also have influenced their perception and stigmas on safe abortion.

According to a qualitative study conducted by Omo-Aghoja LO et al., it was found that the overall perceptions and attitudes were very low among the participants. ${ }^{7}$ Likewise, in a study conducted in Nepal, majority women still lack the knowledge of legalisation of abortion and are unaware about the availability and accessibility of safe abortion services. Stigmas on abortion not only continues in the people of community but even in the service providers and policy makers as well. And the laws regarding the safe abortion has still not rephrased which might create a various challenges further. ${ }^{8} \mathrm{~A}$ review article states that despite the awareness about abortions services among adolescents, they did not acquire much knowledge on abortion legality, pregnancy termination methods and accessibility of safe abortion services. And of course, their attitudes towards abortion were also seen conservative. ${ }^{9}$ In yet another review article, it was found that the accessibility to safe abortion services among adolescents and unmarried girls were very few due to the very limited knowledge about the SRHR. Such reduced accessibility even issued to the unsafe methods of contraception and abortion. ${ }^{10}$

We discovered the majority of women still lack the knowledge and negatively perceive safe abortion in our research as well. Most of our respondents were also very much unaware about the legalisation, amended laws, criteria and accessibility to the safe abortion practices in Nepal. Such lack of knowledge and pessimistic perception can also lead to unsafe abortion practice.

In a qualitative study carried out in the past, abortion was considered as a highly stigmatised topic by the women. Along after the abortion, these attitudes continued to influence disclosure to others as well as women's perception of the reactions of 
others. ${ }^{11}$ In another article by Wilson et al from Mexico, it was found that only $38 \%$ of the people were in support of abortion. Similarly, $63 \%$ and $74 \%$ of the people were in support of abortion in year 2008 and 2009 respectively which was the ultimate increment of support for abortion law in Mexico. The cause for this favour or against in the year 2008 and 2009 were infrequent religious service, secondary and higher education, sex and political parties' affiliation whereas the significant support in the year 2009 were secondary and higher education and infrequent religious service. ${ }^{12}$ Most of the participants in our study were also highly stigmatised on the topic abortion. Due to their negative perception and lack of awareness, most of them even hesitated to talk and discuss about the abortion.

The major limitation of the study was the inability to build the rapport with the participants. Mid-aged women and young girls were more hesitated and were not much interested towards the study. Therefore, their exact reasons behind supporting or not supporting abortion could not be clearly identified. This is relatively a small study involving a small area of the country and hence, the results may not be generalised to the entire nation. However, it is expected that further more elaborate studies are warranted on this topic in the future.

\section{CONCLUSIONS}

Majority of women had very less knowledge and negative perception and more stigmatised towards the abortion. However, more than half of the respondents accepted the abortion. The study also emphasises the need to educate and to make aware every reproductive age woman on safe abortion, its legalisation and its amended law to avoid the stigmas and unsafe abortion practices.

\section{ACKNOWLEDGEMENT}

I am privileged on receiving this opportunity to conduct this research and I would like to express my profound gratitude towards my teachers from Department of Public Health, Nobel College, Mr. Navaraj Bhattarai and Mr. Dirgha Raj Shrestha from Ipas Nepal and Dr. Vivek Shrestha for their invaluable suggestions, encouraging guidance and support and a wise counselling that made this study work a reality.

To cite this article: Shrestha A, Sinha RC, Ahmad A. Knowledge, Acceptability, Perception and Stigmas on Safe Abortion among the women of reproductive age group (15-49 years) in Bhaktapur District. MJSBH. 2021;20(2): $136-41$.

Conflict of Interest: None declared

\section{REFERENCES}

1. Luker K. Abortion and the Politics of Motherhood: University of California Press; 1985.

2. Santé O. Organisation WH, Staff WHO, UNAIDS. Safe Abortion: Technical and Policy Guidance for Health Systems: World Health Organisation; 2003.

3. Thapa S. Abortion Law in Nepal: The Road to Reform. RHM. 2004;12(24):85-94 DOI: 10.1016/ S0968-8080(04)24006-X.

4. Assefa EM. Knowledge, attitude and practice (KAP) of health providers towards safe abortion provision in Addis Ababa health centers. BMC Womens Health. 2019;19(1):138 DOI: 10.1186/s12905-019-0835-x.

5. Sibomana JP, Byiringiro F, Uwanyagasani J, Mpawenimana D. Abortion: Attitudes and knowledge of women in reproductive age in Rwanda. RMJ. 2013;70:9-13 DOI: http://www.bioline.org.br/abstract?id=rw13017\&lang=en.

6. Mara AM, Ayenew M, Haftu H, Aregay B. Assessment of Knowledge and Attitudes of Men and Women Aged between 15-49 Years towards Legalization of Induced Abortion in Mizan Aman Town,Bench Maji Zone, South West Ethiopia, 2016. J Womens Health Care. 2017;6:1-10 DOI: https://doi.org/10.4172/2167-0420.1000376. 
7. Omo-Aghoja LO, Omo-Aghoja VW, Okonofua FE, Aghedo O, Umueri C, Otayohwo R, et al. Perceptions and attitudes of a rural community to abortion in the Niger-delta region of Nigeria. Niger J Clin Pract. 2009;12(4): 443-9. DOI: https://pubmed.ncbi.nlm.nih.gov/20329689/.

8. Shrestha D, Regmi S, Dangal G. Abortion: Still Unfinished Agenda in Nepal. JNHRC. 2018;16:93 DOI: 10.3126/ jnhrc.v16i1.19375.

9. Espinoza C, Samandari G, Andersen K. Abortion knowledge, attitudes and experiences among adolescent girls: a review of the literature. SRHM. 2020;28:1744225 DOI: 10.1080/26410397.2020.1744225.

10. Munakampe MN, Zulu JM, Michelo C. Contraception and abortion knowledge, attitudes and practices among adolescents from low and middle-income countries: a systematic review. BMC Health Serv Res. 2018;18(1):909. DOI: $10.1186 / \mathrm{s} 12913-018-3722-5$.

11. Astbury-Ward E, Parry O, Carnwell R. Stigma, abortion, and disclosure-findings from a qualitative study. J Sex Med. 2012;9(12):3137-47. DOI: 10.1111/j.1743-6109.2011.02604.x.

12. Wilson KS, García SG, Díaz Olavarrieta C, Villalobos-Hernández A, Rodríguez JV, Smith PS, et al. Public opinion on abortion in Mexico City after the landmark reform. Stud Fam Plann. 2011;42(3):175-82. DOI: 10.1111/j. 1728-4465.2011.00279.x. 